\title{
VII. Burmannia Wercklei Schltr. nov. spec. aus Costa Rica.
}

Von R. Schlechter.

(Originaldiagnose.)

In einer kleinen Sammlung von Mjcrospermen, welche ich vor einigen Monaten aus Costa-Rica erhielt, befand sich eine recht interessante Burmannia, die ich hier gesondert beschreiben werde. Die Art ist besonders dadurch merkwürdig, daß sie die zweite amerikanische ist aus einer Gruppe, die sich durch die großen langen Laubblätter und die langen dichotomen Blütenstände mit dichtsitzenden großen Blüten auszeichnet. In meiner Studie über die Burmanniaceen von Deutsch-NeuGuinea ${ }^{1}$ ) habe ich diese Gruppe zu Eu-Burmannia gestellt, da sie sich vor den anderen Eu-Burmannien nur durch die größeren Laubblätter und reicherblütige Infloreszenzen unterscheidet. Auf die charakteristischen Merkmale der Art komme ich weiter unten zurück. Ich will hier nur noch bemerken, daß die einzige Art dieser Verwandtschaft, welche bisher aus Amerika bekannt war, aus Columbien als $B$. Kalbreyeri Oliv. beschrieben worden ist.

Burmannia Wercklei Schltr. nov, spec.

Terrestris, erecta, c. $25 \mathrm{~cm}$ alta; radicibus filiformibus, fasciculatis, glabris; caule simplici bene foliato; foliis erectis vel erecto-patentibus, linearibus, acutis, inferioribus usque ad $12 \mathrm{~cm}$, longis $5 \mathrm{~mm}$ latis, subrosulatis, superioribus sensim in bracteas abeuntibus; inflorescentia dichotoma; brachiis usque ad $8 \mathrm{~cm}$ longis, dense multifloris; bracteis distichis imbricantibus. rhachi appressis, ovato-lanceolatis, acutis, inferioribus usque ad $2 \mathrm{~cm}$ longis, superioribus sensim brevioribus; floribus secundis, graciliter pedicellatis, ut videtur azureis; pedicellis $5-7 \mathrm{~mm}$ longis; floribus in genere longis, $1,3 \mathrm{~cm}$ saepius longitudine excedentibus. angustius trialatis, glabris; corolla tubulosa $5,5 \mathrm{~mm}$ longa, segmentis 3 exterioribus ovatis, acutis, marginibus haud incrassatis, incurvis, c. $2,3 \mathrm{~mm}$ longis, segmentis interioribus carnosulis, oblongo-ligulatis, obtusissimis, quam exteriora triplo brevioribus; staminibus sessilibus supra medium tubi affixis, antheris transversis, connectivo carnoso oblongoideo, lateribus angustato, apice auriculis 2 minutis papillosis donato, loculis parallelis oblongoideis, connectivum haud excedentibus; stylo pro genere brevi, $3 \mathrm{~mm}$ longo, brachiis brevibus; stigmatibus bilabiatis, labio superiore quadrato, amplo, in labium inferiorem brevissimum incumbente; ovario clavato trialato, $7 \mathrm{~mm}$ longo; seminibus nondum maturis anguste oblongoideis.

Costa-Rica: La Palma bei San José, 1750 m ü. d. M. - E. Werckle, in herb. Jimenez no. 687, blühend im April 1910.

Vor B. Kalbreyeri Oliv., der einzigen amerikanischen Art dieser Verwandschaft ist die vorliegende Pflanze gut gekennzeichnet durch die großen breiten Brakteen, die schmalen langen Blüten, die Form des Antherenkonnektivs, den kurzen Griffel und die eigentümlichen Narben.

1) Cf, Engl. Botan. Jahrb. 49, 1912, p. 106. 